\title{
Electrochemical Behavior of Hybrid Films Composed of Copper Hexacyanoferrate and Conducting Polymer
}

\author{
A. A. Hathoot \\ Electrochemistry Laboratory, Chemistry Department, Faculty of Science, Menoufia University, Shebin Elkom, Egypt \\ (E-mail: ablahathoot@yahoo.com)
}

RECEIVED MAY 19, 2011; REVISED AUGUST 10, 2011; ACCEPTED SEPTEMBER 6, 2011

\begin{abstract}
Hybrid organic / inorganic films, composed of poly 4-aminoquinolidine (PAQ) matrix and Prussian blue - like copper hexacyanoferrate $(\mathrm{CuHCFe})$ redox centers were prepared. Platinum disk $(\mathrm{Pt})$ was used as a conductive substrate onto which the hybrid films $(\mathrm{Pt} / \mathrm{PAQ} / \mathrm{CuHCFe})$ were electrodeposited by potential cycling. Electrochemical behavior of the modified electrode was well characterized using cyclic voltammetry technique. The hybrid film modified electrode showed improvement in the electrochemical response in aqueous and non aqueous media compared with the polymer film (PAQ) single layer. Moreover a good electrocatalytic activity towards the oxidation of hydroquinone $\left(\mathrm{H}_{2} \mathrm{Q}\right)$ was observed. In addition, the electrode exhibited a distinct advantage of good chemical and mechanical stability. (doi: 10.5562/cca1920)
\end{abstract}

Keywords: hybrid films, modified electrodes, electropolymerization, electrodeposition, cyclic voltammetry

\section{INTRODUCTION}

Since the pioneering works in the mid-1970s, ${ }^{1}$ the field of chemically modified electrodes (CMEs) has evolved into a widely and intensively researched area. To date, the CMEs in many manifestations have been studied from the fundamental aspects as well as in diverse applications including corrosion inhibition, electrocatalysis, electrochromic biosensing and electroanalysis. ${ }^{2}$ Various organic and inorganic modifiers have been immobilized on electrode surfaces to prepare chemically modified electrodes. ${ }^{3-5}$ Among the inorganic materials, transition metal hexacyanoferrates (MeHCFe) have been studied extensively because of their outstanding properties. These compounds show reversible insertion electrochemistry ${ }^{6,7}$ and electrochromism, ${ }^{8,9}$ the capability to be used in rechargeable batteries $^{10,11}$ and possess electrocatalytic activities. ${ }^{12,13}$ Hybrid materials were obtained as a two layer composition with an organic polymer sub-film and inorganic $\mathrm{MeHCFe}$ cover. Opposite geometry is also proposed in some cases. ${ }^{14-18}$ Despite a sequence in the film preparation, an electrochemical way can be used for synthesis of both polymer and MeHCFe. Chemical way is also applied. ${ }^{17,19}$ The electrochemical deposition process that leads to the formation of the hybrid modified electrode on the Pt electrode surface needs to be carefully controlled. The fabrication of a chemically modified film electrode is easily controlled by using consecutive cyclic voltammetry (CV) synthetic procedure, in which an increase in the peak current of an appropriate redox couple of the modified film indicates that the film is formed. ${ }^{19}$ In our previous study, 4-aminoquinolidine (AQ) was polymerized in aqueous medium to give an electro active film (PAQ). Also, it was shown that the PAQ can be loaded by $\mathrm{Ni}^{2+}$ ions to give stable polymer films with reasonable redox response..$^{20,21}$ This paper aims to improve the PAQ modified electrode by the formation of a composite modified electrode with the inner organic polymer film (PAQ) and the outer layer composed of inorganic $\mathrm{CuHCFe}$ cover. ${ }^{22-26}$ This layer can be formed by the Scheme 1.

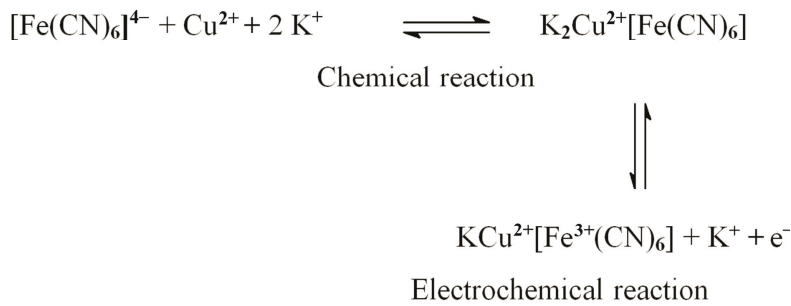

Scheme 1. 
<smiles>Cc1cc(N)c2ccccc2n1</smiles>

Figure 1. The structure of 4-Aminoquinolidine.

\section{EXPERIMENT}

4-aminoquinolidine (AQ), shown in Figure 1, hydrochloric acid $(\mathrm{HCl})$, sulfuric acid $\left(\mathrm{H}_{2} \mathrm{SO}_{4}\right)$, potassium ferrocyanide $\left(\mathrm{K}_{3}\left[\mathrm{Fe}(\mathrm{CN})_{6}\right]\right)$, potassium chloride $(\mathrm{KCl})$, copper chloride $\left(\mathrm{CuCl}_{2}\right)$, lithium chloride $(\mathrm{LiCl})$, sodium chloride $(\mathrm{NaCl})$, cesium chloride $(\mathrm{CsCl})$, ammonium chloride $\left(\mathrm{NH}_{4} \mathrm{Cl}\right)$, acetonitrile $\left(\mathrm{CH}_{3} \mathrm{CN}\right)$, lithium perclorate $\left(\mathrm{LiClO}_{4}\right)$ and hydroquinone $\left(\mathrm{H}_{2} \mathrm{Q}\right)$ were analytical grade chemicals (Aldrich) and were used without further purification. Aqueous solutions were prepared from double distilled water. Electrochemical measurements were carried out using the EG\&G PAR 273 potentiostat with the computer controlled measuring system (model 250) and X-Y Hewlett-Packarad recorder model 7440. A three electrode electrolytic cell (Bioanalytical System, model $\mathrm{C}-1 \mathrm{~A})$ with a platinum disc electrode $(\mathrm{Pt}$, $3.0 \mathrm{~mm}$ diameter), which was the working electrode, a platinum sheet (area $2 \mathrm{~cm}^{2}$ ) as a counter electrode and $(\mathrm{Ag} / \mathrm{AgCl})$ reference electrode were used. Before the modification, the Pt electrode substrate was activated by polishing with successively finer grade aqueous alumina slurries (grain size 5-0.5 $\mu \mathrm{m}$ ) on a polishing cloth. The composite layers of $\mathrm{Pt} / \mathrm{PAQ} / \mathrm{CuHCFe}$ were grown on $\mathrm{Pt}$ by potential cycling using $\mathrm{CV}$ technique in the modification solutions. The first solution contained $10^{-3} \mathrm{M} \mathrm{AQ}$ in $0.2 \mathrm{M}$ aqueous $\mathrm{H}_{2} \mathrm{SO}_{4}$. The electrode was cycled in the potential range between -0.3 and $0.8 \mathrm{~V}$ for 5 cycles, at scan rate $0.1 \mathrm{~V} / \mathrm{s}$. Then it was rinsed by double distilled water, dried and dipped in the aqueous solution containing $0.4 \mathrm{M} \mathrm{HCl}, 0.4 \mathrm{M} \mathrm{KCl}, 10^{-3} \mathrm{M} \mathrm{CuCl}_{2}$ and $0.1 \mathrm{M} \mathrm{K}_{3} \mathrm{Fe}(\mathrm{CN})_{6}$ to deposit the outer later. Typically 20 full potential cycles were applied in the potential range from -0.3 to $1 \mathrm{~V}$, at scan rate $0.1 \mathrm{~V} / \mathrm{s}$. Then the electrode was rinsed by double distilled water and dried. The prepared composite modified electrode was used in further measurements. ${ }^{14,20}$

\section{RESULTS AND DISCUSSION}

\section{Electrochemistry of the Composite Electrode}

The representative cyclic voltammograms recorded at $\mathrm{Pt}, \mathrm{Pt} / \mathrm{PAQ}$ and $\mathrm{Pt} / \mathrm{PAQ} / \mathrm{CuHCFe}$ electrodes are shown in Figure 2 for $0.2 \mathrm{M} \mathrm{NaCl}$. This figure shows that the $\mathrm{Pt} / \mathrm{PAQ}$ modified electrode gives weak redox response, while the $\mathrm{Pt} / \mathrm{PAQ} / \mathrm{CuHCFe}$ composite modified elec-

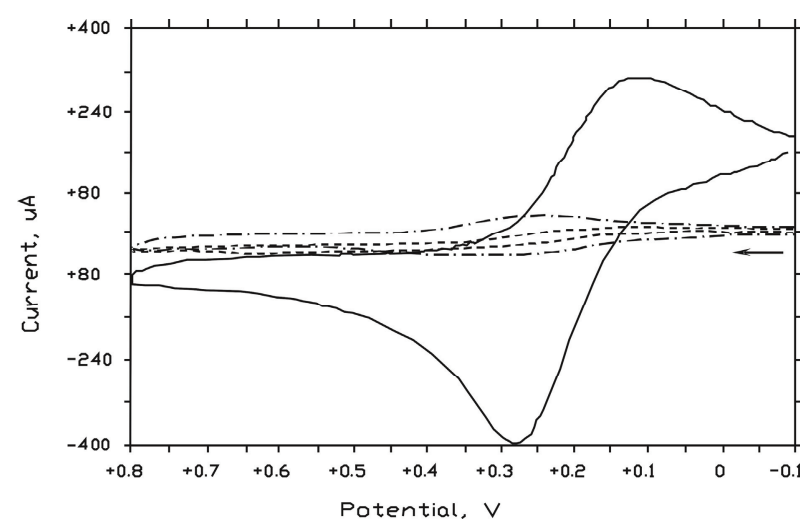

Figure 2. The electrochemical response of (---) bare electrode, (--..) Pt/PAQ modified electrode and (-) PT/PAQ/CuHCFe composite modified electrode in $0.2 \mathrm{M} \mathrm{NaCl}$ solution at scan rate $200 \mathrm{mV} / \mathrm{s}$. The modified electrodes were prepared as it is described in the text.

trode exhibits an oxidation peak at $0.28 \mathrm{~V}$ and the corresponding cathodic peak at $0.14 \mathrm{~V}$. The improvement of the redox response in case of $\mathrm{Pt} / \mathrm{PAQ} / \mathrm{CuHCFe}$ composite electrode could be due to the propagation of charge to the $\mathrm{CuHCFe}$ centers incorporated in the polymeric matrix. It is expected to be fast and the stability is increased. ${ }^{14,21,27}$ In addition, the effect of potential scan rate on the electrochemical properties of $\mathrm{Pt} / \mathrm{PAQ} / \mathrm{CuHCFe}$ were studied in $0.2 \mathrm{M} \mathrm{NaCl}$ aqueous solution by cyclic voltammetry. ${ }^{28-30}$

Factors Affecting the Electrochemical Preparation of the Composite Modified Electrode

The effect of the film thickness (the number of cycles) on the composition and electrochemical characteristics of the resulting films was investigated. The peak current of the redox peaks was taken as an index following the

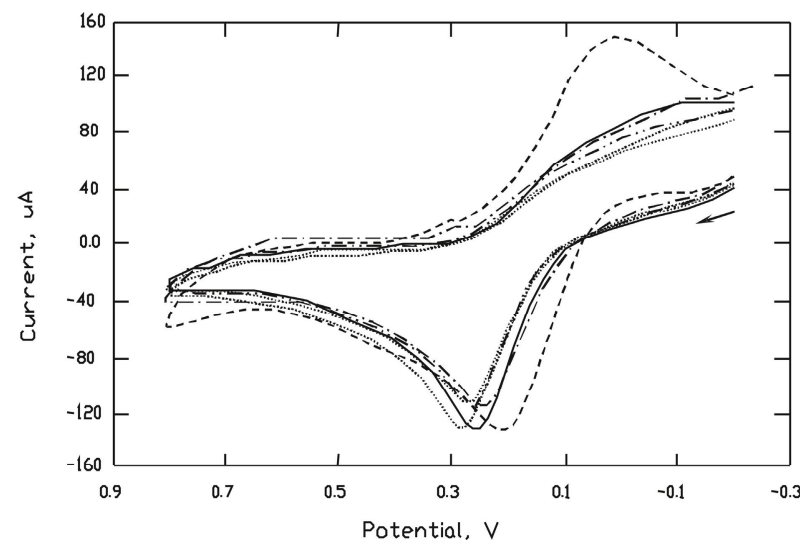

Figure 3. The redox response of $\mathrm{Pt} / \mathrm{PAQ} / \mathrm{CuHCFe}$ composite electrode. The outer layer is prepared in the following potential ranges: (---) -0.3 to $1 \mathrm{~V},(-)-0.3$ to $0.9 \mathrm{~V},(-. .-)-0.3$ to $0.8 \mathrm{~V},(-.-)-0.4$ to $1 \mathrm{~V}$ and $(\cdots)-0.2$ to $1 \mathrm{~V}$, all in $0.2 \mathrm{M} \mathrm{NaCl}$ solution at the scan rate $75 \mathrm{mV} / \mathrm{s}$. The other conditions are as in the text. 


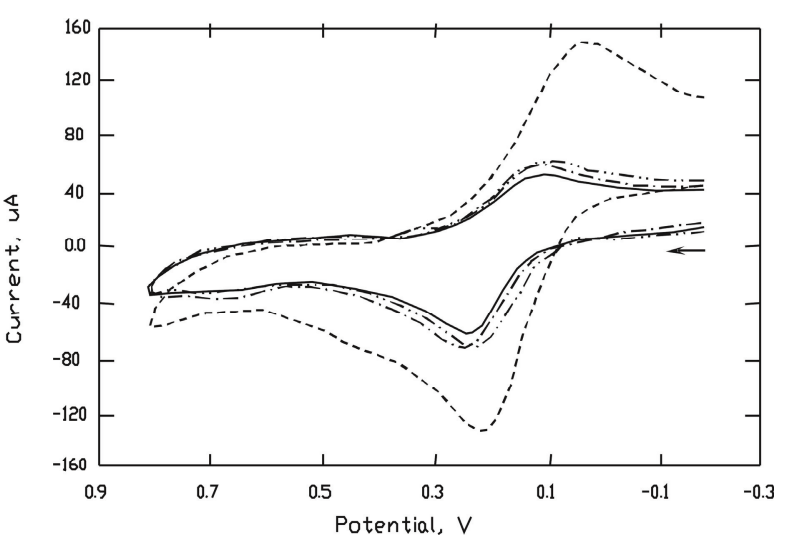

Figure 4. The redox response of $\mathrm{Pt} / \mathrm{PAQ} / \mathrm{CuHCFe}$ composite electrode in $0.2 \mathrm{M} \mathrm{NaCl}$ solution, at scan rate $75 \mathrm{mV} / \mathrm{s}$. The outer layer is prepared in the following concentrations of $\mathrm{KCl}$ : (-..-) $0.2 \mathrm{M},(-.-) 0.3 \mathrm{M},(---) 0.4 \mathrm{M}$ and (-) $0.5 \mathrm{M}$. The other conditions are as in the text.

thickness increase of the polymer film with the number of the cycles used in the polymer film formation. It was found that for the first layer (PAQ) the higher number of cycles decrease the response of the composite film. This observation is in the agreement with our previous results. ${ }^{14,21,28-31}$ The optimal condition of the first layer was found to be 5 scans. The optimal condition of the second layer thickness was also investigated and it was found to be 20 scans. The influence of potential range for first and second layers was studied. It was found that the higher redox currents were obtained when polymerization potential range for the first layer was between -0.3 and $0.8 \mathrm{~V}$ at scan rate $0.1 \mathrm{~V} / \mathrm{s}$. For the second layer Figure 3 shows the effect of the potential range on the redox response of the composite modified electrodes. The best potential range is between $-0.3 \mathrm{~V}$ and $+1 \mathrm{~V}$ at

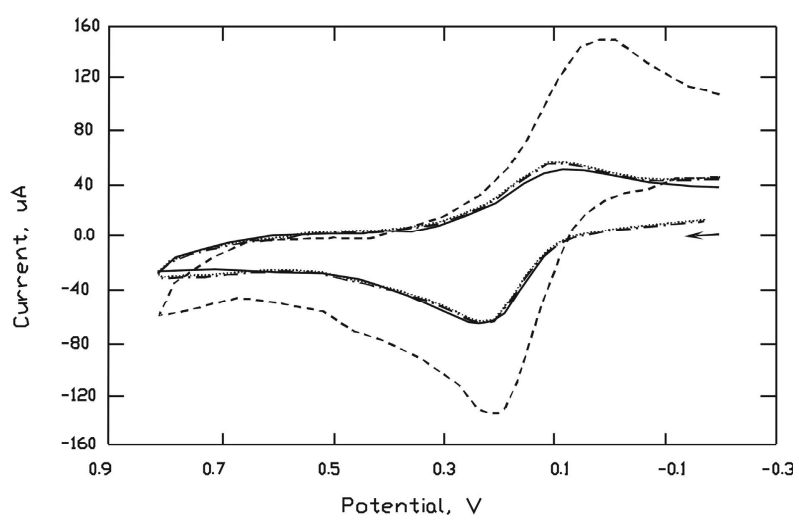

Figure 6. The redox response of $\mathrm{Pt} / \mathrm{PAQ} / \mathrm{CuHCFe}$ composite electrode in $0.2 \mathrm{M} \mathrm{NaCl}$ solution, at scan rate $75 \mathrm{mV} / \mathrm{s}$. The outer layer is prepared in the following concentrations of $\mathrm{K}_{3} \mathrm{Fe}(\mathrm{CN})_{6}:(-) 0.05 \mathrm{M},(\cdots) 0.08 \mathrm{M},(----) 0.1 \mathrm{M}$ and (-..-) $0.2 \mathrm{M}$. The other conditions are as in the text.

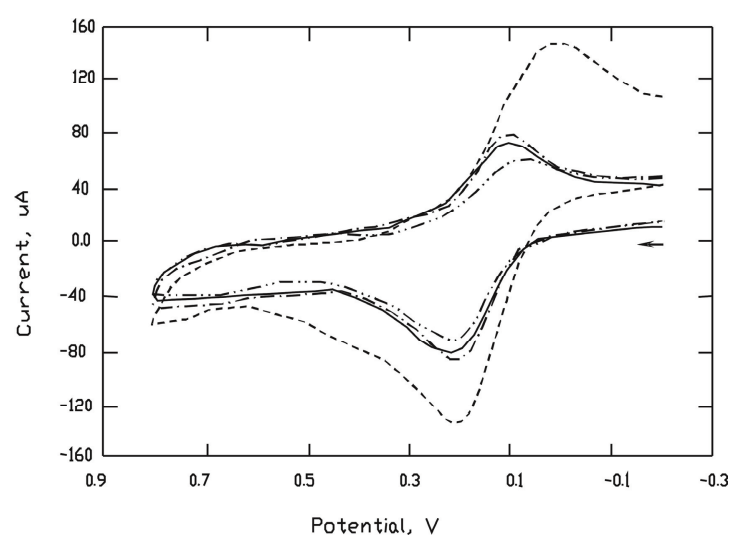

Figure 5. The redox response of $\mathrm{Pt} / \mathrm{PAQ} / \mathrm{CuHCFe}$ composite electrode in $0.2 \mathrm{M} \mathrm{NaCl}$ solution, at scan rate $75 \mathrm{mV} / \mathrm{s}$. The outer layer is prepared in the following concentrations of $\mathrm{CuCl}_{2}$ : (---) $9 \times 10^{-4} \mathrm{M},(---) 1 \times 10^{-3} \mathrm{M},(-.-) 2 \times 10^{-3} \mathrm{M}$ and (-) $3 \times 10^{-3} \mathrm{M}$. The other conditions are as in the text.

scan rate $0.1 \mathrm{~V} / \mathrm{s}$. The electrodeposition of the second layer was carried out from an aqueous solution containing $\mathrm{KCl}, \mathrm{CuCl}_{2}, \mathrm{~K}_{3} \mathrm{Fe}(\mathrm{CN})_{6}$ and $\mathrm{HCl}$. The effect of concentrations of these constituents was investigated. Figures 4-7 show that the concentrations of these compounds can affect the redox response of the resulting modified electrodes, which agrees with the mechanism of the formation of the second layer mentioned in the introduction part. ${ }^{22-26}$ From these figures we can see that the optimum conditions are $0.4 \mathrm{M} \mathrm{KCl}, 1 \times 10^{-3} \mathrm{M}$ $\mathrm{CuCl}_{2}, 0.1 \mathrm{M} \mathrm{K}_{3} \mathrm{Fe}(\mathrm{CN})_{6}$ and $0.4 \mathrm{M} \mathrm{HCl}$.

Permeability of Composite Modified Electrode towards Counter Ion

It has been established that metal hexacyanoferrates show selective permeability towards the cations in the

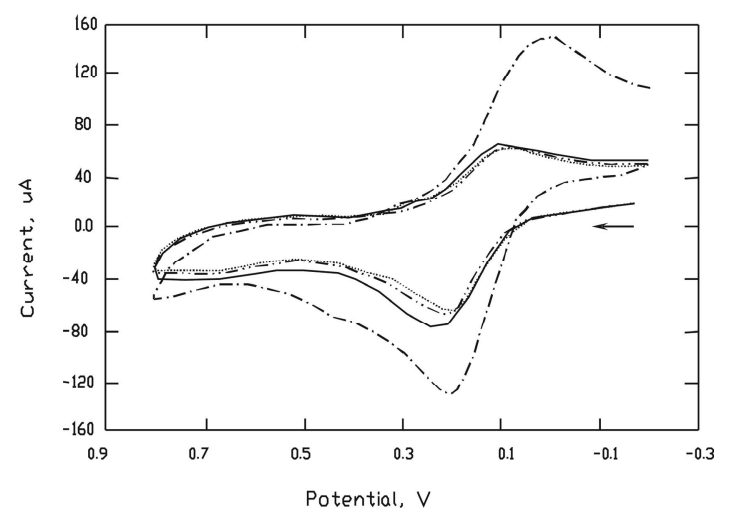

Figure 7. The redox response of $\mathrm{Pt} / \mathrm{PAQ} / \mathrm{CuHCFe}$ composite electrode in $0.2 \mathrm{M} \mathrm{NaCl}$ solution, at scan rate $75 \mathrm{mV} / \mathrm{s}$. The outer layer is prepared in the following concentrations of HCl: (-..-) $0.2 \mathrm{M}$, (-) $0.3 \mathrm{M}$, (-.-) $0.4 \mathrm{M}$ and (...) $0.5 \mathrm{M}$. The other conditions are as in the text. 


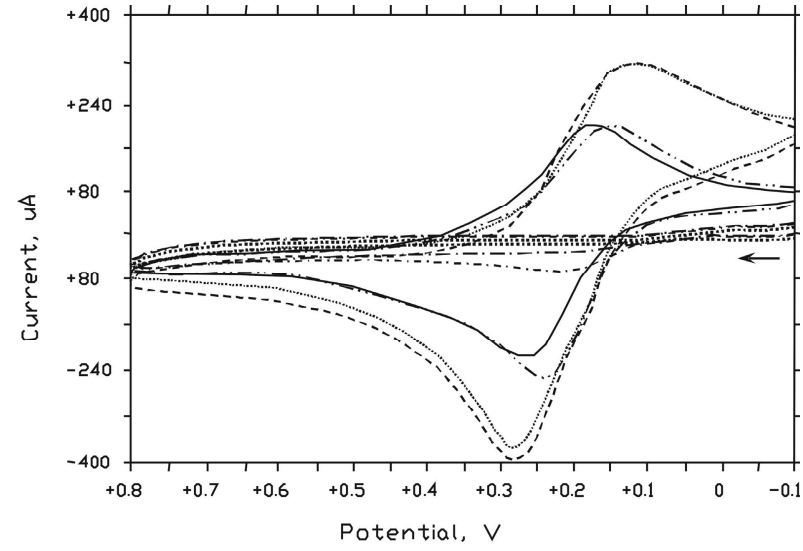

Figure 8. The redox response of $\mathrm{Pt} / \mathrm{PAQ} / \mathrm{CuHCFe}$ composite electrode in $0.2 \mathrm{M}$ of different chloride ion solutions, at scan rate $200 \mathrm{mV} / \mathrm{s}$. The films prepared as in text. (--) $\mathrm{NaCl},(-. .-)$ $\mathrm{NH}_{4} \mathrm{Cl},\left(\_\right) \mathrm{KCl},(-.-) \mathrm{LiCl},(. . . ..) \mathrm{CsCl},(\ldots \ldots \ldots) \mathrm{HCl}$.

supporting electrolyte. Figure 8 shows the cyclic voltammograms of $\mathrm{Pt} / \mathrm{PAQ} / \mathrm{CuHCFe}$ electrodes in $0.2 \mathrm{M}$ aqueous chloride solutions. The results illustrate that the redox response of the composite modified electrode depends on the cation present in the supporting electrolyte. This figure presents comparative cyclic voltammograms for the modified electrode in the six solutions of different supporting electrolytes. It is well known that $\mathrm{CuHCFe}$ film is permeable membrane for cations such as $\mathrm{H}^{+}, \mathrm{Li}^{+}, \mathrm{K}^{+}, \mathrm{Na}^{+}, \mathrm{Cs}^{+}$and $\mathrm{NH}_{4}^{+}$. These cations can react with inorganic film by incorporation into their net structures, to maintain charge balance. The redox process observed is accompanied by the incorporation of cations from the electrolyte solution during the PAQ/ $\mathrm{CuHCFe}$ oxidation/reduction process the cations incorporation is a complicated problem, so several reports indicate that the permeability of hexacyanoferrates depends on hydrated ionic radii of cations. ${ }^{32-37}$ However other reports indicate that the permeability is not in accordance with the order of hydrated ionic radii. ${ }^{38-40}$ Thus the hydrated ionic radius of the insertion ion is not exclusively the determining factor. The permeability of metal hexacyanoferrates towards counter-cations is such complicated problem that there is a great difference in the permeability of the hexacyanoferrates. Besides the radius of the cation, the major factors influencing the permeability of the cation also include the radius of the ion channel in hexacyanoferrates, the interactions between the cation and the hexacyanoferrate, including electrostatic interactions, the ionic polarities, the dehydration ability of the cation before entering the channel of the hexacyanoferrate, etc. ${ }^{41}$ It seems that $\mathrm{Na}^{+}$ion matches the ion channel of CuHCFe most closely and $\mathrm{CuHCFe}$ possesses the best selectivity for $\mathrm{Na}^{+}$ion as a counter ion of the above monocations. This property of the hybrid $\mathrm{CuHCFe}$ may be used for cation recognition. ${ }^{40}$

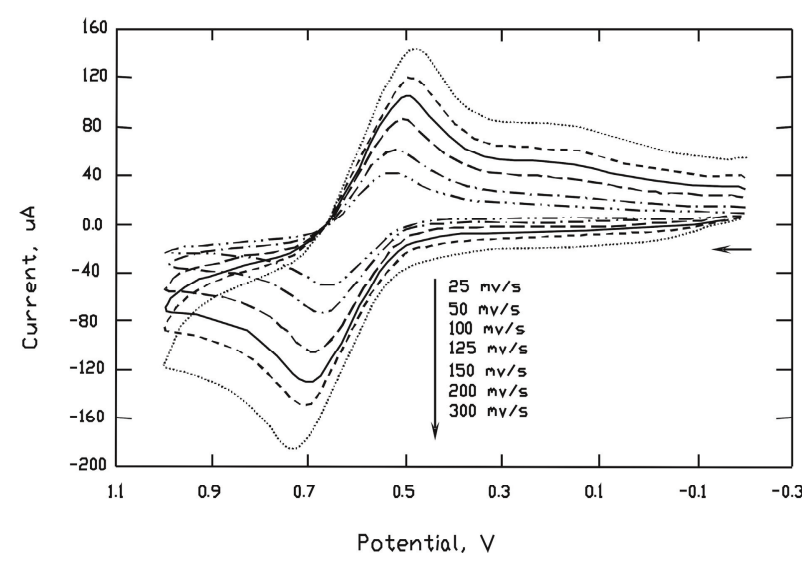

Figure 9. The redox response of $\mathrm{Pt} / \mathrm{PAQ} / \mathrm{CuHCFe}$ composite electrode in $0.1 \mathrm{M} \mathrm{LiClO}_{4} / \mathrm{CH}_{3} \mathrm{CN}$ at different scan rates. The film is prepared as in the text.

The Electrochemical Response of the Composite Modified Electrode in non Aqueous Medium

The redox response of the $\mathrm{Pt} / \mathrm{PAQ} / \mathrm{CuHCFe}$ electrode in $\mathrm{CH}_{3} \mathrm{CN}$ solution containing $0.1 \mathrm{M} \mathrm{LiClO}_{4}$ is shown in Figure 9. The voltammograms exhibit an oxidation peak at $0.72 \mathrm{~V}$ and the corresponding cathodic peak at $0.5 \mathrm{~V}$. The effect of scan rate was studied and shown in the same figure. It illustrates that the redox response increases with scan rate. This means that the composite modified electrode is also electroactive in both aqueous and non aqueous media.

\section{Stability of the Hybrid Modified Electrode}

The stability of the Pt/PAQ/CuHCFe modified electrode was studied during potential cycling and long-term usage. The effect of potential cycling on the hybrid modified electrode was investigated for this purpose. The repetitive cyclic voltammograms were recorded as the potential was scanned between 0 and $0.9 \mathrm{~V}$ ( vs. $\mathrm{Ag} / \mathrm{AgCl}$ ) with scan rate of $0.1 \mathrm{~V} / \mathrm{s}$. It is noticeable that the deposited film is stable for several potential cycles.

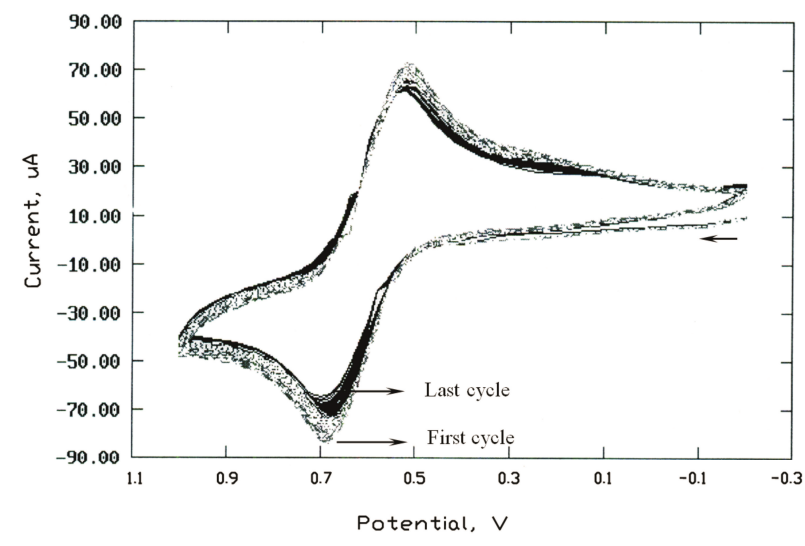

Figure 10. The redox response of $\mathrm{Pt} / \mathrm{PAQ} / \mathrm{CuHCFe}$ composite electrode in $0.1 \mathrm{M} \mathrm{LiClO}_{4} / \mathrm{CH}_{3} \mathrm{CN}$ at $100 \mathrm{mV} / \mathrm{s}$ scan rate, for 150 repetitive scans. The film is prepared as in the text. 
The peak current of the hybrid film was considered as a factor indicating the stability of the modified electrode. The anodic peak potential was unchanged, but the anodic peak current changed somewhat. The modified electrode stability was measured in $0.2 \mathrm{M} \mathrm{NaCl}$ with 200 cycles. Also the stability of the composite electrode was measured in non aqueous medium $\mathrm{CH}_{3} \mathrm{CN} / \mathrm{LiClO}_{4}$. The modified electrode showed good stability in this medium. Figure 10 shows the stability of the composite electrode towards the repetitive cycling (150 scans), recorded as the potential was scanned between -0.3 and $1.0 \mathrm{~V}$ (vs. $\mathrm{Ag} / \mathrm{AgCl}$ ) with scan rate of $0.1 \mathrm{~V} / \mathrm{s}$. The above results indicate that the hybrid modified electrode is fairly stable in aqueous and non aqueous media. This confirms that the formation of hybrid film improves the stability of the modified electrode compared to the single component film.

\section{Electro Catalytic Behavior of Pt/PAQ/CuHCFe Hybrid Film}

Electrolytic oxidation is an effective method to remove organic pollutants e.g. hydroquinone, but usually it is a high energy cost technique due to high oxidation potential and low reduction potential of pollutants. Therefore, the key task for electrolytic oxidation is to lower the oxidation potential or increase the reduction potential, as to reduce the energy cost. Figure 11 illustrates the cyclic voltammograms obtained for the electrooxidation of hydroquinone at $\mathrm{Pt} / \mathrm{PAQ} / \mathrm{CuHCFe}$ composite modified electrode and the naked Pt electrode in $1.5 \mathrm{M}$ $\mathrm{HNO}_{3}$ aqueous solution containing $0.4 \mathrm{M} \mathrm{H}_{2} \mathrm{Q}$ in potential range between -0.4 and $1 \mathrm{~V}$ at scan rate $0.1 \mathrm{~V} / \mathrm{s}$. At naked Pt electrode the anodic peak appears at $0.71 \mathrm{~V}$ and the corresponding cathodic peak appear at $0.0 \mathrm{~V}$. Also the anodic peak current is $26 \mathrm{~mA}$. At the modified electrode the anodic oxidation peak appears at $0.55 \mathrm{~V}$ and the corresponding cathodic peak appears at $0.05 \mathrm{~V}$, and there is an increase in anodic peak current to 30 $\mathrm{mA}$. This indicates that the catalytic effect is visible as a shift of the oxidation potential to less positive values and as a decreasing in gap between the anodic and cathodic potential $\left(E_{\mathrm{pa}}-E_{\mathrm{pc}}=\Delta E\right)$. The increase in the current height illustrates the catalytic effect of $\mathrm{Pt} / \mathrm{PAQ} / \mathrm{CuHCFe}$ composite modified electrode. ${ }^{21,28-31}$

\section{CONCLUSION}

Using consecutive cyclic voltammetry, Pt/PAQ/ $\mathrm{CuHCFe}$ hybrid modified electrode was successfully synthesized directly by deposition of PAQ and then $\mathrm{CuHCFe}$ on the electrode surface. The CuHCFe cover depends on the potential range applied, concentration of the solution constituents during the layer-deposition and also on the nature of electrolyte during the redox response. The nature of cations of the supporting electro-

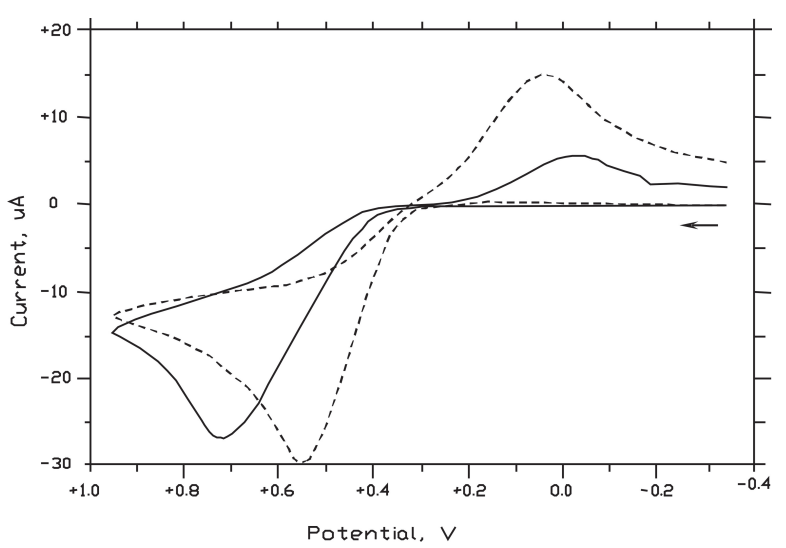

Figure 11. The redox response of $\mathrm{Pt} / \mathrm{PAQ} / \mathrm{CuHCFe}$ composite electrode (---) and bare Pt electrode (-) in $1.5 \mathrm{M} \mathrm{HNO}_{3}$ containing $0.4 \mathrm{M} \mathrm{H}_{2} \mathrm{Q}$. The films are prepared as in the text.

lyte in the redox response process has an important effect on the redox reaction and consequently on the current peak. Hybrid material exhibits high stability and faster ionic transport in comparison with single component film. Stability of the hybrid modified electrode can be studied by using the repeating scan method. The hybrid film shows good stability in aqueous and nonaqueous media compared to the pure one. Electrodes modified with $\mathrm{Pt} / \mathrm{PAQ} / \mathrm{CuHCFe}$ have good electrocatalytic effect towards $\mathrm{H}_{2} \mathrm{Q}$ electrooxidation.

\section{REFERENCES}

1. B. F. Watking, J. R. Behling, E. Kariv, and L. L. Miller, J. Am. Chem. Soc. 97 (1975) 3549-3550.

2. Y. Nakabayashi and H. Yoshikawa, Anal. Sci. 16 (2000) 609-613.

3. R. W. Murray, in: A. J. Bard (Ed.), Electroanalytical Chemistry, vol. 13, Marcel Dekker, NY, 1983, p. 191.

4. R. W. Murray (Ed.), Molecular Design of Electrode Surfaces, vol. XXII, Wiley, New York, 1992.

5. D. Leech, in: M. E. G. Lyons (Ed.), Electroactive Polymers in Electrochemistry, Part 2, Plenum, New York, 1996.

6. K. Itaya, I. Uchida, and V. D. Neff, Acc. Chem. Res. 19 (1986) $162-168$.

7. G. Horanyi, G. Inzelt, and P. J. Kulesza, Electrochim. Acta 35 (1990) 811-816.

8. R. J. Mortimer, J. Electrochem. Soc. 138 (1991) 633-634.

9. P. M. S. Monk, R. J. Mortimer, and D. R. Rosseinsky, Electrochromism: Fundamentals and Applications, VCH, Weinheim, 1995.

10. V. D. Neff, J. Electrochem. Soc. 132 (1985) 1382-1384.

11. M. Jayalakshmi and F. Scholz, J. Power Sources 91 (2000) 217-223.

12. S. Dong and G. Che, J. Electroanal. Chem. 315 (1991) 191-199.

13. M. Shamsipur, M. Najafi, and M. R. Milani Hosseini, Bioelectrochem. 77 (2010) 120-124.

14. A. A. Hathoot, D. Sherif, and M. Abdel-Azeem, Croat. Chem. Acta 83 (2010) 143-149.

15. H. Zhao, Y. Yuan, S. Adeloju, and G. G. Wallace, Anal. Chim. Acta 472 (2002) 113-121.

16. S. Lugu, C. Mihailciuc, L. Pigani, R. Seeber, N. Totir, and C. Zanardi, Electrochem. Commun. 4 (2002) 753-758. 
17. A. Lisowska-Oleksiak, A. P. Nowak, and V. Jasulaitiene, Electrochem. Commun. 8 (2006)107-112.

18. A. Lisowska-Oleksiak, and A. P. Nowak, Solid State Ionics 179 (2008) 72-73.

19. R. Koncki, T. Lenarczuk, and S. Glab, Anal. Chim. Acta $\mathbf{4 2 4}$ (2000) 27-35.

20. M. Abdel-Azzem, Europ. Polymer J. 31(1995) 285-288.

21. A. A. Hathoot, M. Abdel-Kader, and M. Abdel-Azzem, Int. J. Electrochem. Sci. 4 (2009) 208-222.

22. G. Y. Shi, J. X. Lu, F. Xu, W. L. Sun, L. T. Jin, K. Yamamoto, S. G. Tao, and J. Y. Jin, Anal. Chim. Acta 391 (1999) 307-313.

23. S. M. Chen, J. Electroanal. Chem. 417 (1996) 145-153.

24. F. Xu, M. Gao, L. Wang, T. Zhou, L. Jin, and J. Jin, Talanta 58 (2002) 427-432.

25. A. Eftekhari, J. Electroanal. Chem. 537 (2002) 59-99.

26. A. Ernst, O. Makowski, B. Kowalewska, K. Miecznikowski, and P. J. Kulesza, Bioelectrochem. 71 (2007) 23-28.

27. P. J. Kulesza, K. Miecznikowski, M. A. Malik, M. Galkowski, M. Chojak, K. Caban, and A. Wieckowski, Electrochim. Acta 46 (2001) 4065-4073.

28. H. A. Abd-El-Rahman, A. A. Hathoot, M. El-Bagoury, and M. Abdel-Azzem, J. Electrochem. Soc. 147 (2000) 242-247.
29. A. A. Hathoot, Bull. Korean Chem. Soc. 24 (2003) 1609-1912.

30. A. A. Hathoot, Croat. Chem. Acta 84 (2011) 469-473.

31. U. S.Yousef, A. A. Hathoot, and M. Abdel-Azzem, Europ. Polymer J. 37 (2001) 1267-1276

32. E. A. Moelwyn-Hughes, Physical Chemistry, MacMillan Co. Newyork, 1951, p. 589.

33. Z. Gao, Q. Wang, P. B. Li, and Z. F. Zhao, Electrochim. Acta 36(1991) 147-152.

34. P. J. Kulesza and M. Faszynska, J. Electroanal. Chem. 252 (1988) 461-466

35. S. J. Dong and Z. Jin, Electrochim. Acta 34 (1989) 963-968.

36. C.-X. Cai, K.-H.Xue, and S.-M. Xu, J. Electroanal. Chem. 486 (2000) 111-118.

37. Z.-Y. Xun, C.-X. Cai, W. Xing, and T.-H. Lu, J. Electroanal. Chem. 545 (2003) 19-27.

38. X. Cui, L. Hong, and X. Lin. J. Electroanal. Chem. 526 (2002) 115-124.

39. P. Wu and C.-X. Cai, J. Solid Sate. Electrochem. 8 (2004) 538-543.

40. P. Wu, S. Lu, and C.-X. Cai, J. Electroanal. Chem. 569 (2004) $143-150$.

41. P. Wu and C. Cai, J. Electroanal. Chem. 576 (2005) 49-56. 